\title{
The Influence of Low Intensity-High Intensity Plyometric Training and Hand-Eye Coordination on Jump Shoot Ability in Basketball Players of Bhinneka Solo Club: Randomized Control Trial
}

\author{
Putra Hadi $^{1}$, Muchsin Doewes ${ }^{2}$, Slamet Riyadi ${ }^{2}$ \\ ${ }^{1}$ Magister of Sports Science, Universitas Sebelas Maret, Surakarta, Indonesia \\ ${ }^{2}$ Department of Sport Science, Pascasarjana Program, Universitas Sebelas Maret, Surakarta, Indonesia \\ putrahadi915@gmail.com
}

\section{Abstract}

Various studies have been carried out to improve jump shoot ability of basketball, both by simple exercises and modifications to the form of training. The purpose of this study is to determine the influence of low intensity-high intensity plyometric training and hand-eye coordination on jump shoot ability. This study was conducted on basketball players of Bhinneka Solo club. The method used in this study was an experimental method with a $2 \times 2$ factorial design. The sample size in this study was 40 players obtained through purposive sampling. Data analysis techniques in this study used ANOVA, Saphiro Wilk test (Lilliefors test with $\alpha=$ 0.05 ) and homogeneity variance test (Leve's test with $\alpha=0.05$ ). The results show that (1) high intensity plyometric training has a significant influence on jump shoot basketball ability compared to low intensity plyometric training, (2) high hand-eye coordination has a significant influence on jump shoot basketball ability compared to low hand-eye coordination, (3) there is an interaction between low intensity and high intensity plyometric training and hand-eye coordination to jump shoot basketball ability.
Keywords

plyometric training;

basketball; jump shoot;

hand-eye coordination

\section{Introduction}

Basketball is one of the most popular team sports seen and played by people all over the world. Basketball is a group sport consisting of two teams of five people each. The goal of the basketball game is to find as many numbers as possible by inserting the ball in the opponent's basket and preventing the opposing team from scoring. A special level of expertise in sports distinguishes one champion from another. In this sport, through regular and appropriate physical training, technical ability and good conditions are needed to improve ability

The ability that must be possessed by a shooting or shooting basketball player, this becomes one of the basic ability and techniques in basketball. Shooting or shooting can be interpreted as an ability that must be possessed in basketball. In basketball there are many other basic techniques for example: basic techniques such as operands, dribbling, defending, and rebounding. These basic techniques are the deciding factors in scoring, but the role of shooting ability cannot be matched, because this will be a key point in a match. The ability to shoot techniques is good then the abilities of the other basic techniques will be covered. In other words the shooting technique dominates in producing numbers in basketball matches. Needed accuracy in throwing or entering the ball into the basketball ring. It will be more interesting when the player combines shooting with three-point shoot, lay-up shoot and slam- 
dunk (Ahmad, 2007: 5). One shot by a basketball player to put the ball in the ring and get a number is a jump shoot.

To score a number in a competition the technique most commonly used is Jump shoot or shot followed by a jump. Jump shoot movements that are easy to do even though there are several phases of motion carried out include jumping, hand movements in shooting, eyes focused on the target and continued movements to release the ball (Kosasih, 2008: 45). When jump shoot for a basketball, the player must jump up and push a strong arm and aim at the target. This requires strength, leg muscle strength and good arm muscles, so that the expected goals are achieved.

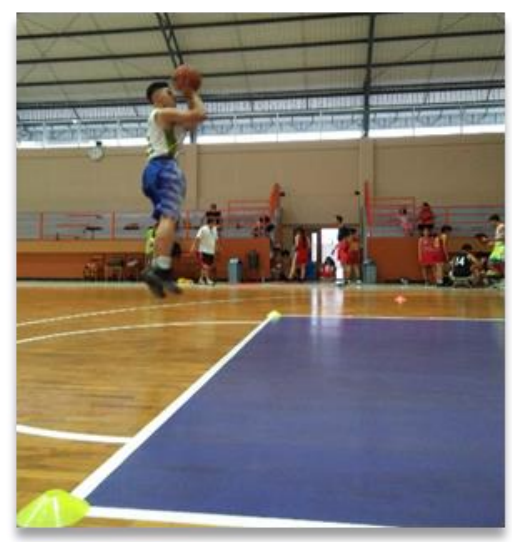

Figure 1. Jump Shoot Basketball Movement

To get a high level of performance in basketball players must find ways to increase maximum muscle strength in the shortest period of time period. There are several methods that can be used including training in plyometric and resistance, usually referred to in the literature as an increase in the characteristics of the most powerful or fast forces to produce maximum strength in basketball players. Several studies have shown positive effects of plyometric and resistance as an indicator to increase maximum strength (Asadi, 2015). Plyometric training are a series of exercises that produce expansive movements by connecting speed and accuracy. This exercise is useful for increasing muscle nerve reaction, speed, and the ability to generate energy in a particular direction. The principle of plyometric training methods makes the muscles always contract both when elongated (eccentric) and shortened (concentric) (Booth \& Rhonda, 2016).

Plyometric training can be done with or without tools. In general, plyometric training have links in sports activities. Stimulating or facilitating various changes in the nervous system of the muscles that aim to increase the ability of the muscle group to be able to respond strongly in a short period of time becomes the initial concept of plyometric training. In various studies on plyometric training, it is stated that plyometric training can improve specific ability in sports such as explosive power (Miller, Et, Al, 2006).

Plyometric training function to produce fast reactions and strong movements. Plyometric training as a link between movements that have speed with strength so as to produce movements that have strong explosive power and are able to do repetitive and cause a rapid motion response. This exercise is also called exercise that gives the effect of maximum muscle strength in the shortest time possible based on shortening contractions followed by elongating very strongly in the same contraction. Before giving a training method, you should look at the factors that can affect your basketball ability. The elements of 
physical conditions such as: flexibility, speed, accuracy, endurance, agility, coordination or a good muscle burst are needed to perform basic basketball ability that are good and regular.

Physical condition is one of the factors that affect appearance when competing. This is closely related to hand-eye coordination which is closely related to the appearance of throwing catches (passing), dribbling and shooting someone's basketball in movement exercises and ability during the competition. The ability of hand-eye coordination is a requirement to achieve maximum performance in basketball players. In this study the authors divided the ability of hand-eye coordination into two namely high and low hand-eye coordination. The hand-eye coordination ability possessed by a player influences the physical ability they have in basketball ability. This becomes a consideration of the training results and character of each player.

The purpose of this study was to examine the influence of plyometric training and hand-eye coordination on jump shoot ability of basketball players.

\section{Research Method}

The type of research used is experimental research that compares two different treatment groups to a predetermined research subject and the research design used is factorial. According to Sudjana (2002: 148), "factorial experiments or experiments where all levels of factors are crossed with all the levels of each other factor in the experiment, with a $2 \times 2$ research design". The subjects in this study were 40 basketball players in Bhinneka Solo Club, which also became the study population, with an average age of 16-18 years. The sample collection technique in this study uses a purposive sampling technique where all populations that are sampled have met the requirements and are in accordance with the objectives of the study. All samples in this study through the process of pretest before action and posttest after action. The hand-eye coordination was measured using a tennis ball throwing test and jump shoot ability data with a jump shoot test basketball (Speed Spot Shooting Test). The plyometric training given in this study were low intensity with splint squat jump and high intensity with double leg vertical power jump movements. The exercises are carried out every week for 3 times for 6 weeks with an overall duration of 90 minutes, beginning with warm up, core and cooling as well as classical practice jump shoot techniques.

The tools and facilities used are basketball field, basketball, throwing equipment for tennis ball and jump shoot test in the form of equipment one (tennis balls, markers and duct tape making boundaries, measuring tape, targets from paper formed in a circle with a diameter of $30 \mathrm{~cm}$ ), equipment two (basketball, stopwatch, basketball field and heet score).

Data in the form of hand-eye coordination and jump shoot ability a basketball for pretest and posttest increase in jump shoot ability a basketball was observed an increase after and after it was treated. Statistical analysis using ANOVA, statistical analysis of data in this study using ANOVA, Saphiro Wilk test (Lilliefors test with $\alpha=0.05$ ) and variance homogeneity test (Leve's test with $\alpha=0.05$ ). 


\section{Discussion}

\subsection{Results}

The results include a statistical analysis to see the frequency distribution of the score of the two training groups, the data normality test which shows the data are normally distributed, the data homogeneity test and the hypothesis test as follows:

\section{a. Frequency Distribution of Two Groups Score}

1) The frequency distribution of group scores increases jump shoot basketball ability training on low intensity

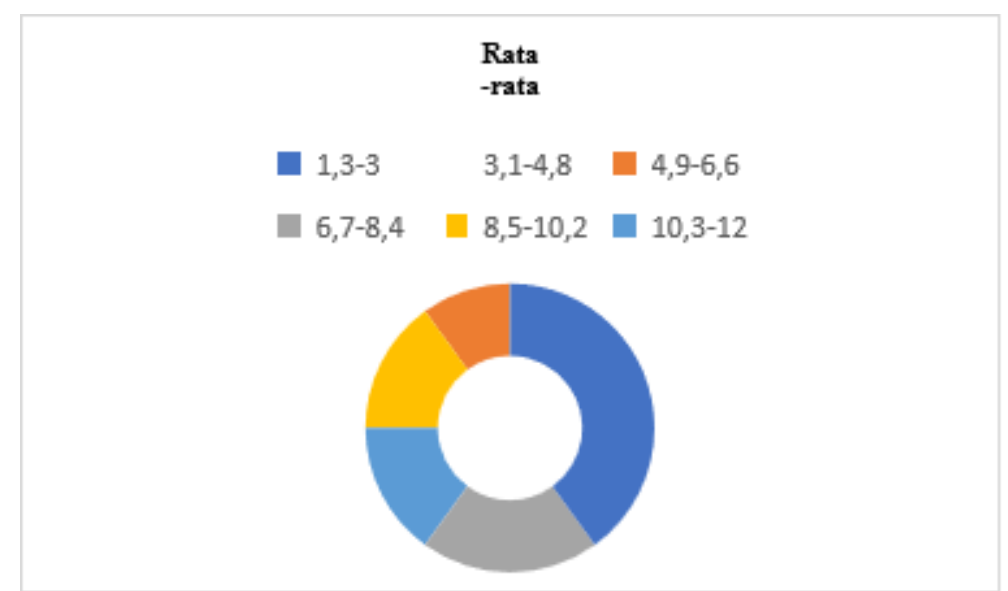

Figure 2. Histogram frequency of jump shoot basketball ability training score on low intensity

2) The frequency distribution of group scores increased jump shoot basketball ability training on high intensity

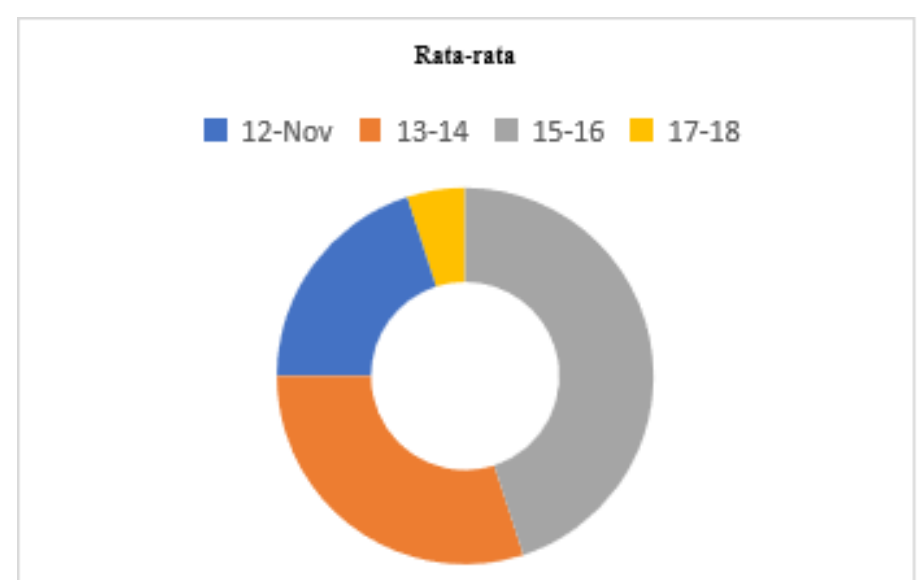

Figure 3. Histogram frequency of jump shoot basketball ability training score on high intensity 


\section{b. Normality Data Test}

Table 1. Pretest Normality Test

Tests of Normality

\begin{tabular}{|l|l|r|r|r|}
\hline & PLYOMETRIC & \multicolumn{3}{|c|}{ Shapiro-Wilk } \\
\cline { 3 - 5 } & & Statistic & \multicolumn{1}{|c|}{ df } & \multicolumn{1}{c|}{ Sig. } \\
\hline PRETEST SCORE & low intensity & 0,954 & 20 & 0,437 \\
JUMPSHOOT & high intensity & 0,973 & 20 & 0,818 \\
POSTEST SCORE & low intensity & 0,926 & 20 & 0,132 \\
JUMPSHOOT & high intensity & 0,914 & 20 & 0,076 \\
\hline
\end{tabular}

${ }^{*}$. This is a lower bound of the true significance.

a. Lilliefors Significance Correction

Table 2. Posttest Normality Test

Tests of Normality

\begin{tabular}{|l|l|r|r|r|}
\hline & HAND-EYE & \multicolumn{3}{|c|}{ Shapiro-Wilk } \\
\cline { 3 - 5 } & COORDINATION & Statistic & Df & \multicolumn{1}{c|}{ Sig. } \\
\hline NILAI PRETEST & Low & 0,960 & 20 & 0,550 \\
JUMPSHOOT & High & 0,972 & 20 & 0,802 \\
NILAI POSTEST & Low & 0,922 & 20 & 0,110 \\
JUMPSHOOT & High & 0,914 & 20 & 0,074 \\
\hline
\end{tabular}

${ }^{*}$. This is a lower bound of the true significance.

a. Lilliefors Significance Correction

From the results of the above tables for all groups of data, all of them have a significance of greater than 0.05 which is the tolerance limit of the saphiro-wilk normality test at a significance level of 5\% with the help of SPSS 16.0 computer programs, namely $(0.954,0.926,0.973,0.914,0.972,0.914,0.960,0.922>0.05)$. Data normality test results using saphiro-wilk showed normal distribution of data ( $p>0.05)$ in all groups both for the pretest and posttest data.

\section{c. Homogeneity Test}

Based on the data in this study, regarding the homogeneity test of the levene's test data for ability test of shoot jump basketball on Bhinneka Solo basketball players in 2019 and analyzed with the help of IBM SPSS 21.0 software, the results show that, the homogeneity test data results in the Plyometric Exercise group has a significance of 0.549 , and the homogeneity of hand-eye coordination test has an arithmetic significance of 0.980 . From the 2 homogeneity tests, all of them have a significance of greater than 0.05 which is the tolerance limit of the levene homogeneity test at a significance level of 5\% with the help of IBM SPSS 21.0 software $(0.549,0.989>0.05)$. Conclusion of the homogeneity test results with the leven's test, it can be concluded that the plyometric exercise test and hand-eye coordination are homogeneous.

\section{d. Hypothesis Test}

Data on group improvement for plyometric training with data on increasing jump shoot results in terms of hand-eye coordination are as follows:

1) Hypothesis I Test (Exercise Model) 
Table 3. Testing of the Plyometric Training Model on Jump Shoot Ability Basketball

\begin{tabular}{|l|c|c|c|c|}
\hline (I) Training Methods & $\begin{array}{c}\text { Mean } \\
\text { Difference (I-J) }\end{array}$ & $\begin{array}{c}\text { Std. } \\
\text { Error }\end{array}$ & F & Sig. \\
\hline $\begin{array}{l}\text { Low Intensity } \\
\text { Plyometric }\end{array}$ & 6,50 & 1,1109 & 27,519 & $<0,001$ \\
\hline $\begin{array}{l}\text { High Intensity } \\
\text { Plyometric }\end{array}$ & 14,4 & 1,0167 & & \\
\hline
\end{tabular}

Table 3 shows that the ANOVA statistical test results were 27,519>3.99, meaning that there were differences in the average ability to jump shoot before and after being given low intensity (6.50) and high intensity (14.4) plyometric training. And from the ANOVA test results obtained p. value $(0.001)<0.05$, then Hol is rejected. This means that there is a significant difference in effect between the low-intensity-high-intensity plyometric training methods on jump shoot ability of basketball in the 2019 Bhinneka Solo Club players.

2) Hypothesis II Test (Hand-Eye Coordination)

Table 4. Hand-eye Coordination Testing

\begin{tabular}{|l|c|c|c|c|}
\hline $\begin{array}{c}\text { (II) Hand-Eye } \\
\text { Coordination }\end{array}$ & $\begin{array}{c}\text { Mean } \\
\text { Difference (I-J) }\end{array}$ & $\begin{array}{c}\text { Std. } \\
\text { Error }\end{array}$ & F & Sig. \\
\cline { 1 - 3 } High & 13,50 & 0,9934 & \multirow{2}{*}{12,695} & $<0,001$ \\
\hline Low & 7.40 & 1,3943 & & \\
\hline
\end{tabular}

Table 4 shows that the statistical results of the ANOVA test are 12,695> 3.99, meaning that there are differences in the average of high and low hand-eye coordination to jump shoot ability viewed from high (13.50) and low hand-eye coordination values (7, 40). And from the ANOVA test results obtained p. value $(0.001)<0.05$, then Ho1 is rejected. This means that there is a significant difference in influence between hand-eye coordination on the jump shoot basketball ability of players in Bhinneka Solo Club in 2019.

3) Hypothesis III Test (Interaction)

Table 5. Testing the Interaction of Plyometric training and Eye-hand Coordination

\begin{tabular}{|c|c|c|c|c|c|c|}
\hline Interaction & Mean & $\begin{array}{c}\text { Std. } \\
\text { Deviation }\end{array}$ & $\mathrm{T}$ & $\mathrm{df}$ & $\begin{array}{l}\text { Sig. (2- } \\
\text { tailed) }\end{array}$ & Information \\
\hline $\begin{array}{c}\text { Plyometric } \\
\text { Training } \\
\end{array}$ & 9,95000 & 5,85706 & 10,744 & \multirow[b]{2}{*}{39} & \multirow[b]{2}{*}{0,001} & \multirow{2}{*}{$\begin{array}{c}\text { There were differences of } \\
\text { influence of low intensity-high } \\
\text { intensity plyometric training } \\
\text { and hand-eye coordination on } \\
\text { jump shoot ability }\end{array}$} \\
\hline $\begin{array}{l}\text { Hand-Eye } \\
\text { Coordination }\end{array}$ & 9,95000 & 5,93534 & 10,602 & & & \\
\hline
\end{tabular}

The results of the study explained that the interaction between the plyometric training methods and eye-hand coordination on jump shoot ability had a significant effect. can be seen from the results of the analysis of variance analysis of 2 factors between plyometric training to jump shoot ability namely $\mathrm{F}$ count $=10.744>\mathrm{F}$ table $=\mathrm{F} 1 ; 39 ; 5 \%=2.021$ thus the null hypothesis (Ho) is rejected, which means there is a significant interaction between the training methods plyometric for jump shoot ability, while in hand-eye coordination the results of the analysis of the variance of two factors between hand-eye coordination to jump shoot ability are $\mathrm{F}$ count $=10,062>\mathrm{F}$ table $=\mathrm{F} 1 ; 39 ; 5 \%=2.021$ thus the null hypothesis $(\mathrm{Ho})$ is 
rejected significant interaction between hand-eye coordination and basketball jump shoot ability.

\subsection{Discussion}

\section{a. Low-Intensity and High-Intensity Plyometric Training on Jump shoot ability of basketball}

Based on hypothesis testing, there is a significant difference in the effect between samples that are treated with low intensity plyometric training with high intensity plyometric training samples to jump shot basketball ability. With the results of the sample given high intensity plyometric training treatments the better results are the jump shoot ability of basketball compared to the sample group that gets low intensity plyometric training.

From the results of data analysis shows that the comparison of the average increase on jump shoot ability of basketball with high intensity plyometric training is higher (14.4) than low intensity plyometric training of (6.50). With the results there are differences in the effect of low intensity and high intensity plyometric training on jump shoot ability of basketball.

\section{b. Jump Shoot Ability of Basketball and Coordination of Hand-Eye, High and Low}

Hypothesis testing has been conducted with the result that there is a significant difference in effect between the first treatment group (high hand-eye coordination ability) and the second treatment group (low hand-eye coordination ability) on jump shoot ability of basketball. In the first treatment group jump shoot ability basketball with an average increase of 13.50 is higher than the second treatment group with an average increase of only 7.40 . It can be concluded that the ability of hand-eye coordination becomes the basis for achieving better jump shoot ability.

The basketball jump shoot movement is a fairly complex movement that must be done in an integrated and harmonious manner, because when jump jump shoot uses a combination of several movements between jump and shot. So the ability to make movements that are integrated and harmonized by the player influences the success of the basketball jump shoot. Controlled movements when jump shoot basketball shoots improve accuracy in shooting the ball into the ring, this is influenced by good eye-handcoordination. Players who have high hand-eye coordination have the ability to be faster and better at mastering basketball jump shoot ability, than players who have low hand-eye coordination.

From the results in the analysis of the data showed that the comparison of the average increase in basketball jump shoot ability in players who have high hand-eye coordination is 13.50 which is higher than in the group of players who have low hand-eye coordination.

\section{c. Plyometric Training and Hand-Eye Coordination on Jump Shoot of Basketball Ability}

Based on the analysis of the two-factor variant, the results show that the main factors of research in the form of two factors show a real interaction. The lines do not appear to be parallel or crossed by changes in the value of jump shoot ability, but both lines have a meeting point between the use of plyometric training methods and hand-eye coordination. So it can be interpreted that there is a significant interaction between the two. From these results stated that hand-eye coordination affects jump shoot ability of basketball. 


\section{Conclusion}

Based on the results of research on the influence of low intensity and high intensity plyometric training and hand-eye coordination on jump shoot ability of basketball on club players of Bhinneka Solo, the results show that:

1. High intensity plyometric training have a significant influence on jump shoot ability of basketball compared to low intensity plyometric training, so it can be concluded the influence of high intensity plyometric training is better than low intensity plyometric training.

2. High eye-hand coordination has a significant influence on jump shoot ability of basketball compared to low eye-hand coordination, so it can be concluded that the influence of high eye-hand coordination is better than low eye-hand coordination on the results of the basketball shoot jump ability.

3. There are interactions in plyometric training and hand-eye coordination on basketball jump shoot ability, it can be concluded as follows:

a. High intensity plyometric training are more suitable given to players who have high hand-eye coordination

b. Low intensity training are more suitable given to players who have low eye-hand coordination.

From the conclusions above in this study, it produces an implication in designing a plyometric training program, specifically in determining the right training to be used in improving basketball jump shoot ability on players, so that coaches, trainers and athletes of basketball need to pay attention to methods, techniques and strategy precisely and well. The methods, techniques and strategies used are the best and are carried out to the maximum. Characteristics of players and training must be in accordance with the selected exercise.

The results of this study indicate that in high intensity plyometric training exercises get better and optimal results compared to low intensity plyometric training. From the results obtained, this high intensity plyometric training can be used as a solution and consideration for trainers, coaches and tips in increasing jump shoot ability of basketball. The process of training the basketball jump shoot ability, must pay attention to the characteristics of players and become a benchmark for determining the training methods, forms of training strategies to be programmed is one of them hand-eye coordination. Players who have high hand-eye coordination will find it easier to master the basketball jump shoot ability, so the quality of players who have high hand-eye coordination can be said to be better than players who have low hand-eye coordination.

From the above review, the players' differences in hand-eye coordination will have implications for coaches, trainers and advisors in determining the methods, techniques and forms of training that are appropriate in the training process of jump shoot in basketball.

Based on the results of this study, the coaches, trainers and athletes were given the following suggestions:

1. For fostering the achievements of Bhinneka Solo Club, it is necessary to socialize the low intensity plyometric training and high intensity plyometric training always given every training as an effort to achieve jump shoot ability of basketball.

2. For coaches and trainers, in an effort to achieve jump shoot ability of basketball players should select the seeds of players well. Then given the physical training methods and jump shoot training that supports the achievement of the basketball jump shoot ability for players so that the training method will be more efficient. 
3. Provision of training methods to improve basketball jump shoot ability, it is necessary to pay attention to factors that are one of them hand-eye coordination.

4. Trainers and coaches in providing the training to improve basketball shoot jump ability can use low intensity and high intensity plyometric training.

\section{Acknowledgement}

Thank you especially to the players, coaches and managers of Bhinneka Solo Club and the mentors who helped with this research.

\section{References}

Ahmad, N. 2007. Permainan olahraga Bola basket. Surakarta: Era Intermedia.

Asadi, A. 2015. Effects Of High-Intensity Plyometric Training On Dynamic Balance, Agility, Vertical Jump And Sprint Performance In Young Male Basketball Players. Journal of Sport and Health Research.4 (1):35-44.

Booth A.M, Rhonda Orr. 2016. Effects of Plyometric Training on Sports Performance. National Strength and Conditioning Association. Unauthorized reproduction of this article is prohibited.Volume 38 No.1 februari 2016.

Hansen D, kennely S. 2017. Plyometric Anatomy. United States: Human Kinetics.

Kosasih, D. 2008. Fundamental Basket Ball, First Step To Win. Semarang : Karangturi Media. Yayasan Pendidikan Nasional Karangturi.

Miller, Michael,G.,et al. 2006. "The Effects Of A 6-Week Plyometric Training Program On Agility”. JSSM. September 2006. pp. 459-465.

Shankar et al. 2008. Effect of High Intensity and Low Intensity Plyometric on Vertical Jump Height and Maximum Voluntary Isometric Contraction in Football Players. Journal of Exercise Science and Physiotherapy (JESP) Volume 4, No. 2. Hal. 81: 2008.

Shaji, J dan Isha, S. 2009. Comparative analysis of plyometric training program and dynamic stretching on vertical jump and agility in male collegiate basketball player. AlAmeenJ.Med.Sci (2009)2 (1 ):3 6-4 6

Sudjana. 2002. Desain \& Analisis Eksperimen. Edisi IV. Bandung: Penerbit Tarsito.

Wissel, Hal. 2000. Basketball Dilengkapi dengan Program Pemahiran Teknik dan Taktik. Jakarta: PT. Rajagrafindo Persada. 